\title{
Early versus late arteriovenous malformation responders after stereotactic radiosurgery: an international multicenter study
}

\author{
Or Cohen-Inbar, MD, PhD, ${ }^{1}$ Robert M. Starke, MD, MSc, ${ }^{1,9}$ Gabriella Paisan, BA, ${ }^{1}$ \\ Hideyuki Kano, MD, PhD, ${ }^{2}$ Paul P. Huang, MD, ${ }^{3}$ Rafael Rodriguez-Mercado, MD, ${ }^{4}$ \\ Luis Almodovar, MD, ${ }^{4}$ Inga S. Grills, MD, ${ }^{5}$ David Mathieu, MD, ${ }^{6}$ Danilo Silva, MD, ${ }^{7}$ \\ Mahmoud Abbassy, MD, ${ }^{7}$ Symeon Missios, MD, ${ }^{7}$ John Y. K. Lee, MD, ${ }^{8}$ Gene H. Barnett, MD, MBA, ${ }^{7}$ \\ Douglas Kondziolka, MD, ${ }^{3}$ L. Dade Lunsford, MD, ${ }^{2}$ and Jason P. Sheehan, MD, PhD ${ }^{1}$ \\ ${ }^{1}$ Department of Neurosurgery and Gamma Knife Center, University of Virginia, Charlottesville, Virginia; ${ }^{2 D e p a r t m e n t ~ o f ~}$ \\ Neurosurgery, University of Pittsburgh, Pennsylvania; ${ }^{3}$ Department of Neurosurgery, New York University Langone Medical \\ Center, New York, New York; ${ }^{4}$ Department of Neurosurgery, University of Puerto Rico, San Juan, Puerto Rico; ${ }^{5}$ Department of \\ Radiation Oncology, Beaumont Health System, Royal Oak, Michigan; ' ${ }^{6}$ Department of Neurosurgery, University of Sherbrooke, \\ Centre de Recherche Clinique Étienne-LeBel, Sherbrooke, Quebec, Canada; ${ }^{7}$ Rose-Ella Burkhardt Brain Tumor and Neuro- \\ Oncology Center, Cleveland Clinic, Cleveland, Ohio; ${ }^{8}$ Department of Neurosurgery, University of Pennsylvania, Philadelphia, \\ Pennsylvania; and ${ }^{2}$ Department of Neurological Surgery and Radiology, University of Miami, Florida
}

OBJECTIVE The goal of stereotactic radiosurgery (SRS) for arteriovenous malformation (AVM) is complete nidus obliteration, thereby eliminating the risk of future hemorrhage. This outcome can be observed within the first 18 months, although documentation of AVM obliteration can extend to as much as 5 years after SRS is performed. A shorter time to obliteration may impact the frequency and effect of post-SRS complications and latency hemorrhage. The authors' goal in the present study was to determine predictors of early obliteration (18 months or less) following SRS for cerebral AVM. METHODS Eight centers participating in the International Gamma Knife Research Foundation (IGKRF) obtained institutional review board approval to supply de-identified patient data. From a cohort of 2231 patients, a total of 1398 patients had confirmed AVM obliteration. Patients were sorted into early responders (198 patients), defined as those with confirmed nidus obliteration at or prior to 18 months after SRS, and late responders (1200 patients), defined as those with confirmed nidus obliteration more than 18 months after SRS. The median clinical follow-up time was 63.7 months (range 7-324.7 months).

RESULTS Outcome parameters including latency interval hemorrhage, mortality, and favorable outcome were not significantly different between the 2 groups. Radiologically demonstrated radiation-induced changes were noted more often in the late responder group (376 patients [31.3\%] vs 39 patients [19.7\%] for early responders, $p=0.005)$. Multivariate independent predictors of early obliteration included a margin dose $>24 \mathrm{~Gy}(p=0.031)$, prior surgery $(p=0.002)$, no prior radiotherapy $(p=0.025)$, smaller AVM nidus $(p=0.002)$, deep venous drainage $(p=0.039)$, and nidus location ( $p$ $<0.0001)$. Basal ganglia, cerebellum, and frontal lobe nidus locations favored early obliteration $(p=0.009)$. The Virginia Radiosurgery AVM Scale (VRAS) score was significantly different between the 2 responder groups $(p=0.039)$. The VRAS score was also shown to be predictive of early obliteration on univariate analysis $(p=0.009)$. For early obliteration, such prognostic ability was not shown for other SRS- and AVM-related grading systems.

CONCLUSIONS Early obliteration ( $\leq 18$ months post-SRS) was more common in patients whose AVMs were smaller, located in the frontal lobe, basal ganglia, or cerebellum, had deep venous drainage, and had received a margin dose > 24 Gy.

https://thejns.org/doi/abs/10.3171/2016.7.JNS161194

KEY WORDS radiosurgery; Gamma Knife; arteriovenous malformation; early obliteration; embolization; vascular disorders; stereotactic radiosurgery

ABBREVIATIONS AVM = arteriovenous malformation; GKRS = Gamma Knife radiosurgery; IGKRF = International Gamma Knife Research Foundation; MRA = MR angiography; RBAS = Radiosurgery-Based AVM score; RIC = radiation-induced change; SM = Spetzler-Martin; SRS = stereotactic radiosurgery; VRAS = Virginia Radiosurgery AVM Scale.

SUBMITTED May 9, 2016. ACCEPTED July 11, 2016.

INCLUDE WHEN CITING Published online September 23, 2016; DOI: 10.3171/2016.7.JNS161194. 
$\mathrm{T}$ HE goal of stereotactic radiosurgery (SRS) for arteriovenous malformations (AVMs) is complete obliteration of the nidus, thereby eliminating the risk of future hemorrhage. ${ }^{26,38}$ Obliteration rates are reported to vary between $70 \%$ and $80 \%{ }^{13,18}$ and are associated with a relatively low risk profile for adverse radiation effects. ${ }^{1,20}$ An initial radiological response to SRS is often observed within the first 6-18 months. ${ }^{15,21,35}$ Patients who demonstrated such a response may be called "early responders," whereas documented obliteration may not occur for up to 5 years (late responders) in other AVM patients. The present study was designed to identify which factors affect early versus late AVM responses to SRS.

\section{Methods}

\section{Patient Population}

Eight medical centers participating in the International Gamma Knife Research Foundation (IGKRF) each obtained institutional review board approval to participate in this study. A total of 1398 patients with obliterated AVMs were identified, all of whom had undergone Gamma Knife radiosurgery (GKRS) between 1988 and 2014. During this interval, a total of 2231 patients had undergone radiosurgery for AVMs. At each center, a retrospective review of clinical and radiological patient outcome parameters was performed. The centers contributing data for this study were the University of Virginia (702 patients), University of Pittsburgh (469 patients), Cleveland Clinic (85 patients), New York University (47 patients), Beaumont Health System (37 patients), University of Sherbrooke, Centre de Recherche Clinique (29 patients), University of Pennsylvania (24 patients), and University of Puerto Rico (5 patients).

Each center reviewed the medical records of their patients and entered their information into a database, and investigators removed all patient identifiers from the database. Pooled and de-identified data were screened by the IGKRF study coordinator for errors, and data were verified for compliance with patient privacy and the protection of patient information. Any uncertainties or ambiguities in the data were addressed by the contributing center.

All patients had imaging confirmation of AVM obliteration and a minimum of 6 months of neuroimaging and clinical follow-up. Nidus obliteration was confirmed with angiography, MR angiography (MRA), or both. Patients were sorted into 2 groups: early responders, defined as those whose AVMs were obliterated at or before 18 months after SRS, and late responders, defined as those whose AVMs were obliterated more than 18 months after SRS. The latter group included patients who had undergone repeat SRS if their AVM was patent at 3 or more years after the initial SRS. Patients treated with volumestaged or hypofractionated SRS were not included in our analysis. Demographic, medical, and clinical parameters of the patients were logged at different time points. Detailed clinical and radiological presentations as well as outcome parameters were recorded. Neurological examination, complications, and deficits were also recorded in the database.

\section{Radiosurgical Technique}

Gamma Knife models U, B, C, 4C, or Perfexion were used during the study period, depending on the technology available at the time for each participating center. The Leksell model G stereotactic frame (Elekta AB) was applied using a local anesthetic supplemented with additional sedation as needed. High-resolution stereotactic MRI was then performed. When MRI was not feasible or if MRI distortion was a concern, stereotactic CT scanning was performed. Thin-slice axial and/or coronal plane images were obtained after intravenous contrast administration. Stereotactic cerebral angiography was incorporated into the treatment planning for nidus definition. Multidisciplinary radiosurgery dose planning was then performed by a neurosurgeon in collaboration with a radiation oncologist and a medical physicist.

In this series, the mean margin and maximum doses delivered to the nidus were not significantly different between the 2 responder groups, and neither was the planned isodose line. The margin dose for early versus late responders was $21.7 \pm 3.1$ Gy and $21.4 \pm 3.2$ Gy, respectively $(\mathrm{p}=0.249)$. The maximal dose for early versus late responders was $40.3 \pm 6.8 \mathrm{~Gy}$ and $39.9 \pm 7 \mathrm{~Gy}$, respectively $(\mathrm{p}=0.4)$. The treatment isodose line was $55.2 \% \pm 11.3 \%$ and $54.6 \% \pm 10.4 \%$ for early versus late responders, respectively $(\mathrm{p}=0.528)$. Dose selection was determined at each center by weighting the factors of nidus volume, prior neurological deficits, proximity to critical structures, and prior fractionated radiation therapy. Radiosurgical parameters are detailed in Table 1.

\section{Clinical and Radiological Assessment After SRS}

Clinical and neuroimaging evaluations were generally performed at follow-up intervals of 6 months for the first 2 years after SRS and annually thereafter. Patients' followup evaluations included neurological examination and neuroimaging (most often MRI) at the respective treating center. When MRI suggested AVM obliteration (absent of vascular flow voids on T2-weighted imaging), patients typically underwent a diagnostic cerebral angiography or MR angiography (MRA) to confirm nidus obliteration. If the AVM was still patent 3-4 years after initial SRS, retreatment with SRS was performed in selected patients.

Follow-up was continued even after evidence of AVM obliteration. Every 1-5 years, patients were evaluated to detect any long-term complications. Whenever possible, clinical and radiological evaluations were performed at the respective treating center. In selected cases patients underwent clinical follow-up with their local physicians. For such patients, clinical notes and actual neuroimaging studies (not just the radiological reports) were reviewed by the treating clinician who had performed the SRS procedure. Follow-up images were compared with the images obtained at the time of SRS. A favorable outcome was defined as AVM obliteration without a latency interval hemorrhage or permanent symptomatic radiation-induced changes (RICs). Such changes were termed "transient" if they resolved or "permanent" if they were associated with persistent new neurological signs plus unresolved increased perinidal T2-weighted MRI changes. 
TABLE 1. Summary of patient and AVM-related parameters in those with early and late nidus obliteration

\begin{tabular}{|c|c|c|c|}
\hline Parameter & $\begin{array}{c}\text { Early } \\
\text { Responders }\end{array}$ & $\begin{array}{c}\text { Late } \\
\text { Responders }\end{array}$ & $\begin{array}{c}\mathrm{p} \\
\text { Value* }\end{array}$ \\
\hline No. of patients & $198(14.2 \%)$ & $1200(85.8 \%)$ & \\
\hline$M: F$ & $\begin{array}{c}103: 95 \\
(52 \%: 48 \%)\end{array}$ & $\begin{array}{c}602: 598 \\
(50.2 \%: 49.8 \%)\end{array}$ & 0.629 \\
\hline Mean age in yrs & $37.2 \pm 17.8$ & $35.3 \pm 16.1$ & 0.134 \\
\hline Previous radiotherapy & $9(4.5 \%)$ & $128(10.7 \%)$ & 0.007 \\
\hline Prior surgery & $20(10.1 \%)$ & $51(4.2 \%)$ & 0.001 \\
\hline Prior embolization & $22(11.1 \%)$ & $187(15.6 \%)$ & 0.526 \\
\hline History of hemorrhage & $104(52.5 \%)$ & $657(54.8 \%)$ & 0.56 \\
\hline \multicolumn{4}{|l|}{ Symptoms } \\
\hline None & $4(2 \%)$ & $34(2.8 \%)$ & \multirow{5}{*}{0.575} \\
\hline Bleeding & $104(52.5 \%)$ & $657(54.8 \%)$ & \\
\hline Seizures & $37(18.7 \%)$ & $232(19.3 \%)$ & \\
\hline Headache & $39(19.7 \%)$ & $188(15.7 \%)$ & \\
\hline Neurological changes & $11(5.6 \%)$ & $87(7.3 \%)$ & \\
\hline Mean max diameter (cm) & $1.96 \pm 1.02$ & $2.12 \pm 1.05$ & 0.039 \\
\hline Mean vol $\left(\mathrm{cm}^{3}\right)$ & $3.2 \pm 4.4$ & $3.3 \pm 3.4$ & 0.64 \\
\hline Aneurysm & $22(11.1 \%)$ & $118(9.8 \%)$ & 0.308 \\
\hline \multicolumn{4}{|l|}{ AVM nidus location† } \\
\hline Frontal & $39(19.7)$ & $205(17.1)$ & \multirow{10}{*}{0.009} \\
\hline Temporal & $25(12.6)$ & $187(15.6)$ & \\
\hline Parietal & $32(16.2)$ & $203(16.9)$ & \\
\hline Occipital & $20(10.1)$ & $156(13)$ & \\
\hline Thalamic & $13(6.6)$ & $106(8.8)$ & \\
\hline Basal ganglia & $22(11.1)$ & $85(7.1)$ & \\
\hline Corpus callosum & $4(2)$ & $56(4.7)$ & \\
\hline Brainstem & $11(5.6)$ & $93(7.8)$ & \\
\hline Cerebellum & 27 (13.6) & $82(6.8)$ & \\
\hline Insula & $2(1)$ & $22(1.8)$ & \\
\hline \multicolumn{4}{|l|}{ SM classification } \\
\hline \multicolumn{4}{|l|}{ Size } \\
\hline 1 & $169(85.4 \%)$ & $998(83.2 \%)$ & \multirow{3}{*}{0.403} \\
\hline 2 & $28(14.1 \%)$ & $199(16.6 \%)$ & \\
\hline 3 & $1(0.5 \%)$ & $3(0.25 \%)$ & \\
\hline Eloquence & $132(66.7 \%)$ & $802(66.8 \%)$ & 0.963 \\
\hline Venous drainage & $124(62.6 \%)$ & $645(53.8 \%)$ & 0.02 \\
\hline \multicolumn{4}{|l|}{ Gradef } \\
\hline I & $20(10.1 \%)$ & $160(13.3 \%)$ & \multirow{5}{*}{0.168} \\
\hline II & $76(38.4 \%)$ & $499(41.6 \%)$ & \\
\hline III & $94(47.5 \%)$ & $463(38.6 \%)$ & \\
\hline IV & $8(4 \%)$ & $74(6.2 \%)$ & \\
\hline V & $0(0 \%)$ & $3(0.25 \%)$ & \\
\hline \multicolumn{4}{|l|}{ VRAS scores§ } \\
\hline 0 & $17(8.7 \%)$ & $79(6.6 \%)$ & \multirow{5}{*}{0.039} \\
\hline 1 & $67(34.2 \%)$ & $350(29.2 \%)$ & \\
\hline 2 & $62(31.6 \%)$ & $329(27.4 \%)$ & \\
\hline 3 & $30(15.3 \%)$ & $289(24.1 \%)$ & \\
\hline 4 & $20(10.2 \%)$ & $152(12.7 \%)$ & \\
\hline
\end{tabular}

CONTINUED IN NEXT COLUMN
» CONTINUED FROM PREVIOUS COLUMN

TABLE 1. Summary of patient and AVM-related parameters in those with early and late nidus obliteration

\begin{tabular}{|c|c|c|c|}
\hline Parameter & $\begin{array}{c}\text { Early } \\
\text { Responders }\end{array}$ & $\begin{array}{c}\text { Late } \\
\text { Responders }\end{array}$ & $\begin{array}{c}p \\
\text { Value }^{*}\end{array}$ \\
\hline \multicolumn{4}{|l|}{ VRAS scores§ (continued) } \\
\hline $0-2$ & $146(74.5 \%)$ & $758(63.2 \%)$ & \multirow{2}{*}{0.002} \\
\hline $3-4$ & $50(25.5 \%)$ & $441(36.8 \%)$ & \\
\hline \multicolumn{4}{|l|}{ RBAST } \\
\hline 0 & $16(8.2 \%)$ & $77(6.4 \%)$ & \multirow{4}{*}{0.285} \\
\hline 1 & $75(38.5 \%)$ & $437(36.4 \%)$ & \\
\hline 2 & $67(34.4 \%)$ & $493(41.1 \%)$ & \\
\hline 3 & $37(19 \%)$ & $192(16 \%)$ & \\
\hline \multicolumn{4}{|l|}{ Treatment parameters } \\
\hline Mean max dose (Gy) & $40.3 \pm 6.8$ & $39.9 \pm 7$ & 0.4 \\
\hline Mean margin dose (Gy) & $21.7 \pm 3.1$ & $21.4 \pm 3.2$ & 0.249 \\
\hline Mean isodose (\%) & $55.2 \pm 11.3$ & $54.6 \pm 10.4$ & 0.528 \\
\hline \multicolumn{4}{|l|}{ Obliteration confirmed } \\
\hline Angiography & $139(70.2 \%)$ & $957(79.75 \%)$ & \multirow{2}{*}{0.148} \\
\hline MRA & $59(29.8 \%)$ & $243(20.25 \%)$ & \\
\hline
\end{tabular}

* Boldface type indicates significance.

† Locations in 3 cases among the early responders and 5 cases among the late responders were not clearly specified and are not reflected.

‡ The SM grade could not be determined in 1 case among the late responders because of insufficient information.

$\S$ The VRAS score could not be calculated in 2 cases among the early responders and 1 case among the late responders because of insufficient information.

II The RBAS could not be determined in 3 cases among the early responders and 1 case among the late responders because of insufficient information.

\section{Statistical Analysis}

Data are presented as the median or mean \pm standard deviation and range for continuous variables and as the frequency and percentage for categorical variables. Calculations of normality were assessed graphically and statistically. Statistical analyses of categorical variables were performed using chi-square and Fisher's exact tests as appropriate. Statistics of means were performed using an unpaired Student t-test both with and without equal variance (Levene's test) as necessary and Wilcoxon rank-sum tests when variables were not normally distributed. Favorable outcome was defined as AVM obliteration and no posttreatment hemorrhage or permanent symptomatic complications following treatment. Eloquence was assessed according to the Spetzler-Martin (SM) grading scale, ${ }^{28}$ location was defined according to the updated ${ }^{25}$ version of the modified Radiosurgery-Based AVM score (RBAS), and the Virginia Radiosurgery AVM Scale (VRAS) was defined as originally described (Table 1$) \cdot{ }^{30}$ Competing risk survival analysis of AVM-free obliteration was calculated using the modified Kaplan-Meier method and Gray's method. ${ }^{9}$ After confirming the assumption of proportional hazards, we entered factors predictive of obliteration $(\mathrm{p}<$ 0.15 ) into a modified multivariate Cox regression analysis to assess hazard ratios in the presence of competing mortality risk (mHR). ${ }^{5}$ Youden indices were calculated to determine cutoffs for the dichotomized continuous variable 
margin dose (Gy) that yielded the optimal discrimination of early obliteration. A p value $\leq 0.05$ was considered statistically significant.

\section{Results \\ Cohort Overview}

The specific patient and AVM attributes are detailed in Table 1. Males formed 50.4\% (705 patients) of the cohort, and the number of males was not significantly different between early and late responders $(\mathrm{p}=0.629)$. The mean age was $37.2 \pm 17.8$ years in early responders and $35.3 \pm$ 16.1 years in the late responders $(\mathrm{p}=0.134)$. Nonsignificant differences were noted for other AVM parameters such as pre-SRS embolization ( $\mathrm{p}=0.526$ ); prior nidus hemorrhage $(\mathrm{p}=0.56)$; presenting symptoms such as headaches, seizures, neurological changes, or no symptoms $(\mathrm{p}=0.575)$; associated aneurysm $(\mathrm{p}=0.308)$; $\mathrm{SM}$ grade-based size grouping $(\mathrm{p}=0.403)$ or eloquence $(\mathrm{p}=0.963)$; or $\mathrm{RBAS}^{25}$ $(\mathrm{p}=0.285)$.

Significantly more late responders underwent prior AVM radiation procedures, either conventional radiotherapy or SRS (128 [10.7\%] vs 9 [4.5\%], p = 0.007), and had a larger mean nidus diameter $(2.12 \pm 1.05 \mathrm{~cm}$ vs $1.96 \pm$ $1.02 \mathrm{~cm}, \mathrm{p}=0.039$ ). A comparison of mean nidus volumes revealed no statistical significance $\left(3.2 \pm 4.4 \mathrm{~cm}^{3}\right.$ vs $3.3 \pm$ $\left.3.4 \mathrm{~cm}^{3}, \mathrm{p}=0.64\right)$. Significantly more early responders had prior microsurgical resection $(20$ [10.1\%] vs 51 [4.2\%], p = $0.001)$. Early responders tended to have AVMs located in the frontal lobes, basal ganglia, and cerebellum $(19.7 \%$ vs $17.1 \%, 11.1 \%$ vs $7.1 \%$, and $13.6 \%$ vs $6.8 \%$, respectively, $\mathrm{p}=$ 0.009). Early responders more often had AVMs with deep venous drainage (124 [62.6\%] vs 645 [53.8\%], $\mathrm{p}=0.02)$. The VRAS score ${ }^{30}$ was shown to be significantly different between the 2 groups, both for each grade separately ( $\mathrm{p}=$ 0.039 ) and when grouped by VRAS Scores $0-2$ and 3-4 $(\mathrm{p}=0.002)$.

\section{Assessment of Dose and Complications}

The different outcome parameters are summarized in Table 2. Actuarial obliteration rates at 3, 6, 9, 12, and 15 months post-SRS in the early responders were $14 \%$, $23.2 \%, 36.5 \%, 48 \%$, and $79.4 \%$, respectively. The KaplanMeier actuarial rate of obliteration for early responders is demonstrated in Fig. 1. For the entire study cohort, the mean clinical follow-up time was $86 \pm 64.6$ months (range 6-324.7 months), the mean MRA follow-up time was 57.4 \pm 52.4 months (range 6-264.3 months), and the mean angiographic follow-up time was $42.1 \pm 34.2$ months (range 6-324.7 months). The incidence of overall post-SRS latency period hemorrhage was low in the entire cohort and was not statistically significant between the 2 groups ( $2.5 \%$ early vs $4.5 \%$ late responders, $p=0.202)$. This held true when reviewing annual post-SRS latency hemorrhage as well (2.5\% early vs $3.9 \%$ late responders for 1 st year and $0 \%$ vs $0.6 \%$, respectively, for 2 nd year). No delayed hemorrhages were observed in patients with angiographic confirmation of obliteration. The median clinical followup time was 63.7 months (range 7-324.7 months).

Radiation-induced changes were significantly detected more often in late responders (31.3\% late vs $19.7 \%$ early
TABLE 2. Outcome in patients with early and late nidus obliteration

\begin{tabular}{|c|c|c|c|}
\hline Parameter & $\begin{array}{c}\text { Early } \\
\text { Responders }\end{array}$ & $\begin{array}{c}\text { Late } \\
\text { Responders }\end{array}$ & $p$ Value* \\
\hline \multicolumn{4}{|c|}{$\begin{array}{l}\text { Post-GKS latency period } \\
\text { hemorrhage }\end{array}$} \\
\hline Overall & $5(2.5 \%)$ & $54(4.5 \%)$ & 0.202 \\
\hline 1 st yr & $5(2.5 \%)$ & $47(3.9 \%)$ & \multirow{2}{*}{0.526} \\
\hline 2nd yr & $0(0 \%)$ & $7(0.6 \%)$ & \\
\hline \multicolumn{4}{|l|}{ RICs } \\
\hline Radiologic & $39(19.7 \%)$ & $376(31.3 \%)$ & 0.005 \\
\hline Symptomatic & $15(7.5 \%)$ & $119(9.9 \%)$ & 0.468 \\
\hline Permanent & $6(3 \%)$ & $28(2.3 \%)$ & 0.431 \\
\hline Death & $6(3 \%)$ & $26(2.2 \%)$ & 0.886 \\
\hline Unfavorable outcome & $9(4.5 \%)$ & $78(6.5 \%)$ & 0.421 \\
\hline \multicolumn{4}{|l|}{ Margin dose in Gy } \\
\hline$<18$ & $34(17.2 \%)$ & $239(19.9 \%)$ & \multirow{5}{*}{0.047} \\
\hline $18-20$ & $56(28.3 \%)$ & $315(26.3 \%)$ & \\
\hline $20-22$ & $21(10.6 \%)$ & $121(10.1 \%)$ & \\
\hline $22-24$ & $27(13.6 \%)$ & $252(21 \%)$ & \\
\hline$>24$ & $60(30.3 \%)$ & $273(22.8 \%)$ & \\
\hline
\end{tabular}

* Boldface type indicates significance.

responders, $\mathrm{p}=0.005$ ). There was no statistically significant difference between groups when symptomatic or permanent RICs were compared (9.9\% late vs $7.5 \%$ early responders, $\mathrm{p}=0.468$ for symptomatic RICs; and $2.3 \%$ vs $3 \%$, respectively, $\mathrm{p}=0.431$ for permanent RICs). Overall mortality rates were comparable between the 2 groups ( $2.2 \%$ late vs $3 \%$ early responders, $p=0.886)$. Favorable outcome (that is, AVM nidus obliteration without postSRS latent phase hemorrhage or permanent SRS-associated RICs) was not found to differ significantly between the 2 groups $(\mathrm{p}=0.421)$.

As shown in Table 2, patients who received a higher margin dose were more likely to have early AVM nidus obliteration. In reviewing the margin dose to the nidus, we found that a significantly larger percentage of early responders was treated with AVM margin doses $>24$ Gy (30.3\% early vs $22.8 \%$ late responders, $p=0.047$ ), whereas a significantly larger percentage of late responders was treated with margin doses of $22-24$ Gy (21\% late vs $13.6 \%$ early responders, $\mathrm{p}=0.047$ ).

\section{Predictors of Early AVM Response}

Independent predictors of early response in univariate and multivariate logistic regression analyses are summarized in Table 3. On univariate analysis, predictors of early response included no prior radiation procedures (HR 0.42, $\mathrm{p}=0.011,95 \%$ CI $0.215-0.82)$, prior partial resection (HR $2.305, \mathrm{p}<0.0001,95 \%$ CI 1.451-3.659), a smaller maximal nidus diameter (HR 0.825, $\mathrm{p}=0.029,95 \%$ CI 0.694 0.98), more recent SRS (HR 1.069, p < 0.0001, 95\% CI $1.048-1.091$ ), margin dose $>24$ Gy (HR 1.411, $\mathrm{p}=0.026$, 95\% CI 1.042-1.911), deep venous drainage (HR 1.391, $\mathrm{p}=$ $0.025,95 \%$ CI 1.043-1.855), and lower VRAS score (HR $0.846, \mathrm{p}=0.009,95 \%$ CI $0.746-0.959$ ). 


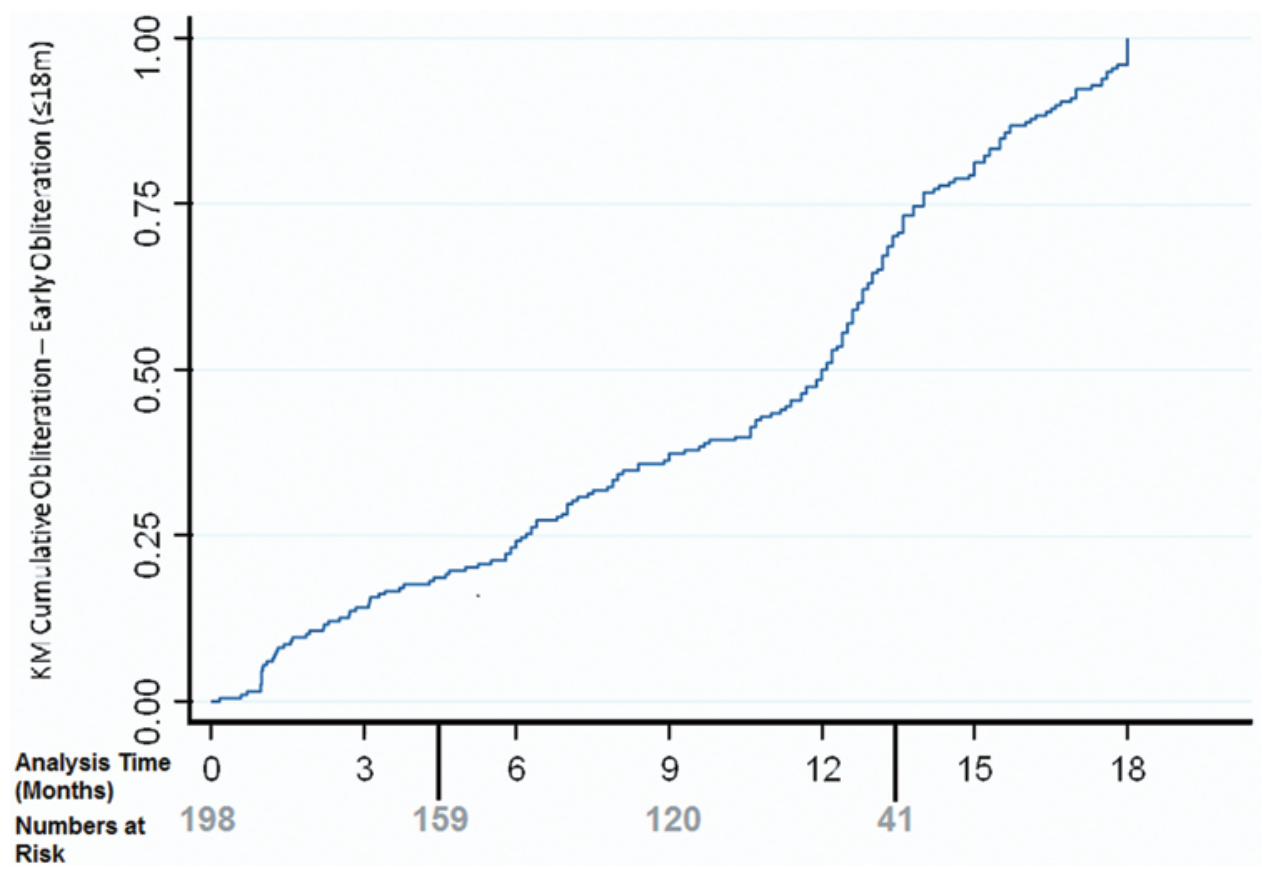

FIG. 1. Kaplan-Meier (KM) plot. Obliteration rate of the early responders. Figure is available in color online only.

Predictors of early response in the multivariate logistic regression analysis similarly included no prior radiation procedures (HR 0.463, $\mathrm{p}=0.025,95 \%$ CI $0.236-0.908$ ), prior partial resection (HR 2.071, $\mathrm{p}=0.002,95 \%$ CI 1.297 3.307), a smaller maximal nidus diameter (HR 0.735, $\mathrm{p}=$ $0.002,95 \%$ CI $0.607-0.891$ ), a margin dose $>24$ Gy (HR $1.712, \mathrm{p}=0.031,95 \%$ CI $1.05-2.793)$, and deep venous drainage (HR 1.369, $\mathrm{p}=0.039,95 \%$ CI 1.016-1.844; Table 3 ). Nidus location (frontal lobe, basal ganglia, and cerebellum) was also predictive of an early response (HR 1.718, p $<0.0001,95 \%$ CI 1.286-2.297).

\section{Discussion}

Arteriovenous malformations continue to represent a significant clinical challenge, and expert opinions differ regarding their optimal management. ${ }^{1}$ Treatment goals can vary among patients: reducing seizure activity, ameliorating symptomatic chronic "vascular steal," or alleviating neurological deficits caused by associated cerebral edema. However, the main goal of any intervention for AVMs remains complete obliteration of the nidus, thereby eliminating subsequent risk of hemorrhage. Most clinicians report that AVM response to SRS occurs slowly and incrementally, reaching a maximum benefit within 3 years. Yet, most reports indicate that a subset of patients has obliteration in less than half that time. Identifying factors associated with early obliteration could alter risk assessment and aid in decision making for both physicians and patients.

\section{Predictors of Early AVM Obliteration}

The response of an individual brain AVM to SRS cannot be completely predicted on the basis of its radiological appearance. While early response is seen in some patients, final documentation of AVM closure may not be recorded for many years, depending on the timing of the followup examination and the willingness of patients to undergo definitive imaging studies. ${ }^{35}$ Oppenheim et al. ${ }^{23}$ observed that no more than $38 \%$ of AVMs will show delayed closure if less than $50 \%$ of the nidus is occluded at 1 year. In contrast, $84 \%$ of AVMs will be obliterated if $75 \%$ of the nidus is occluded at 1 year. Reported AVM obliteration rates at 1 year vary between $29 \%$ and $76 \%$. $^{2,7,17,31,37}$

In 2006, Nagaraja et al. ${ }^{21}$ reported on quantitative MR assessment of the AVM nidal response at 1 year and angiographic factors predicting early obliteration. They studied a cohort of 40 consecutive patients with 41 AVMs treated using GKRS. Eight AVM parameters were documented for each AVM. These variables were then correlated with 3 categories of response in terms of percentage nidal reduction using Fisher's test (slow 0-49\%, fast 50\%-99\%, and complete 100\%). The authors reported a $22 \%$ obliteration rate at 1 year post-SRS. The parameters reviewed were maximum linear dimension, nidus volume, nidus location (subdivided into cortical, subcortical, combined, basal ganglia, posterior fossa, and brainstem), nidus type (diffuse vs compact), venous drainage (location and multiplicity of venous outflow), prior embolization, dose reduction (due to location, nidus size, or prior SRS), and flow rate. Flow was deemed high if there was simultaneous opacification of the artery pedicles and nidus and venous outflow on the first image or if a shunt was present. The presence of arterial irregularity and/or stenosis, related aneurysm, or venous stenosis was also indicative of high flow per the author's methodology. Two AVM factors were noted to significantly correlate with the rate of obliteration: deep versus superficial venous drainage and nidus location..$^{21}$

The anatomical location of the AVM was earlier report- 
TABLE 3. Factors influencing early obliteration ( $\leq 18$ months) of AVMs in 1398 cases: Cox regression model

\begin{tabular}{|c|c|c|c|c|c|c|}
\hline \multirow[b]{2}{*}{ Potential Factors } & \multicolumn{3}{|c|}{ Multivariate Predictors } & \multicolumn{3}{|c|}{ Univariate Predictors } \\
\hline & $\mathrm{HR}$ & p Value* & $95 \% \mathrm{Cl}$ & $\mathrm{HR}$ & p Value* & $95 \% \mathrm{Cl}$ \\
\hline Age & 1.007 & 0.104 & $0.998-1.015$ & 1.006 & 0.128 & $0.998-1.015$ \\
\hline Sex & 1.094 & 0.528 & $0.827-1.446$ & & & \\
\hline No previous RT & 0.463 & 0.025 & $0.236-0.908$ & 0.42 & 0.011 & $0.215-0.82$ \\
\hline Prior surgery & 2.071 & 0.002 & $1.297-3.307$ & 2.305 & $<0.0001$ & $1.451-3.659$ \\
\hline Prior embolization & 0.898 & 0.643 & $0.572-1.411$ & 0.863 & 0.523 & $0.55-1.354$ \\
\hline Smaller nidus vol & - & - & - & 0.99 & 0.677 & $0.948-1.034$ \\
\hline Smaller maximal nidus diameter & 0.735 & 0.002 & $0.607-0.891$ & 0.825 & 0.029 & $0.694-0.98$ \\
\hline Prior hemorrhage & 0.981 & 0.899 & $0.738-1.305$ & 0.923 & 0.576 & $0.698-1.22$ \\
\hline Nidus location† & 1.718 & $<0.0001$ & $1.286-2.297$ & - & - & - \\
\hline \multicolumn{7}{|l|}{ Peripheral dose } \\
\hline Continuous & 1.004 & 0.865 & $0.953-1.058$ & 1.024 & 0.277 & $0.98-1.069$ \\
\hline$>18 \mathrm{~Gy}$ & 1.49 & 0.054 & $0.993-2.236$ & 1.167 & 0.41 & $0.807-1.689$ \\
\hline$>20 \mathrm{~Gy}$ & 1.516 & 0.064 & $0.975-2.355$ & 1.025 & 0.861 & $0.775-1.356$ \\
\hline$>22 \mathrm{~Gy}$ & 1.652 & 0.08 & $0.942-2.901$ & 1 & 0.995 & $0.755-1.325$ \\
\hline$>24 \mathrm{~Gy}$ & 1.712 & 0.031 & $1.05-2.793$ & 1.411 & 0.026 & $1.042-1.911$ \\
\hline Maximal dose & - & - & - & 1.009 & 0.375 & $0.989-1.029$ \\
\hline Isodose & - & - & - & 1.003 & 0.614 & $0.99-1.016$ \\
\hline Perinidal aneurysm & - & - & - & 1.149 & 0.539 & $0.737-1.789$ \\
\hline \multicolumn{7}{|l|}{ SM score } \\
\hline Overall & - & - & - & 1.107 & 0.253 & $0.929-1.319$ \\
\hline Nidus size & - & - & - & 0.899 & 0.586 & $0.613-1.318$ \\
\hline Eloquence & - & - & - & 0.986 & 0.927 & $0.733-1.325$ \\
\hline Deep venous drainage & 1.369 & 0.039 & $1.016-1.844$ & 1.391 & 0.025 & $1.043-1.855$ \\
\hline RBAS & - & - & - & 0.966 & 0.694 & $0.814-1.146$ \\
\hline VRAS & - & - & - & 0.846 & 0.009 & $0.746-0.959$ \\
\hline
\end{tabular}

ed to bear a significant correlation with response., $414,21,36$ Cortically located AVMs showed a better response in one study, ${ }^{14}$ while another group has shown a better response with more deep-seated lesions. ${ }^{19}$ High-flow compartments within AVMs were shown by some groups to be associated with incomplete or poor response to treatment. ${ }^{24}$ Other groups failed to show such an effect of "high-flow vasculopathy" features or rapid arteriovenous shunting as predictors of early obliteration. ${ }^{21}$ Inoue et al. ${ }^{12}$ reported significantly higher rates of early AVM obliteration in slowand low-flow AVMs (73.9\%) as compared with high-flow AVMs (18.2\%). The authors postulated that the higher early obliteration rates stemmed not from decreasing the size of the AVM nidus by embolization but rather by decreasing their flow rate and flow volume. This hypothesis could not be verified by other groups. ${ }^{12}$ Fukuoka et al. ${ }^{8}$ reported that rapid-flow-rate AVMs are more radiobiologically resistant, even if they are small, because they contain large-diameter vessels. The authors explained their finding by hypothesizing that SRS leads to targeted blood vessel endothelial and medial thickening, which occurs earlier in smaller-diameter vessels. ${ }^{8}$

The present series consists of 1398 patients whose cere- bral AVMs had documented complete AVM obliteration. Among this cohort, 198 patients had an early response ( $\leq 18$ months after SRS) after initial SRS and 1200 patients had a later response (> 18 months from initial SRS). Comparing these 2 groups revealed differences from prior studies that evaluated prognostic parameters. In reviewing the early responders, several key factors emerged (Table 1). Prior radiotherapy (or prior SRS) seems to confer a lower rate of early response $(p=0.007)$, although our analysis may reflect a selection bias related to the often larger volume of the target, incomplete response to an initial radiation procedure, and the use of a reduced margin dose at the time of SRS. Prior partial resection supports an early response $(\mathrm{p}=0.001)$ perhaps because of a smaller residual target volume. A smaller nidus diameter supports early response as well $(\mathrm{p}=0.039)$. Basal ganglia, cerebellum, and frontal lobe nidus locations favor early response $(\mathrm{p}=$ 0.009), which may be partially explained by the fact that the presence of deep venous drainage favors early obliteration as well $(\mathrm{p}=0.02)$.

We were unable to document differences in response rates for a number of other factors (Table 2). Radiologic RICs were noted more often in the late responders, but we 
found no significant difference in symptomatic or permanent RICs between early and late responders. Radiationinduced changes typically develop 12-18 months post-SRS and, unless symptomatic or permanent, bear little clinical significance except to herald future obliteration. ${ }^{1}$ A higher margin dose was previously reported to be a key predictor of obliteration, $, 13,6,10,22,30,38$ which was not demonstrated in this cohort. In the present report of AVM patients, all of whom had obliteration, we found that those who received a margin dose $>24 \mathrm{~Gy}$ responded sooner. The topographical location of the AVM nidus in the frontal lobes, basal ganglia, and cerebellum was shown to predict early obliteration as well ( $\mathrm{p}<0.0001)$.

The exact pathophysiology for early obliteration of an AVM remains uncertain. A higher radiosurgical dose, feasible in smaller AVM volumes with an acceptable risk profile, indicates the importance of dose volume considerations in individual patients. Endothelial cell and myofibroblast proliferation mediated by cytokine release are likely increased by the higher dose. ${ }^{27,32,33}$ The presence of deep venous drainage and other cerebrovascular features in many early obliterated AVMs may also point to additional angioarchitectural features that favor early obliteration. ${ }^{34}$

\section{Value of Outcome Predictor Models}

The current study also highlights the limitations of the SM AVM grading system when applied to predicting SRS outcomes. The RBAS, known to be a valuable tool for predicting overall obliteration, ${ }^{25}$ was not found to be useful in identifying early responders. The VRAS score, however, both according to individual grade and grouped by VRAS Scores 0-2 and Scores 3-4, was significantly different between the 2 groups $(p=0.039$ and 0.002 , respectively; Table 1). The VRAS was also predictive on univariate analysis $(p=0.009)$. Since the VRAS is relatively newer than the SM and RBAS grading systems, it has yet to be subjected to the same rigorous external testing. In 2015, Huo et al. ${ }^{11}$ reported on a cohort of 162 patients with partially embolized AVMs who underwent SRS. The authors reported that the VRAS was predictive of AVM obliteration (VRAS Scores 0-1, 2, 3, and 4 resulted in obliteration rates of $89 \%, 68 \%, 51 \%$, and $35 \%$, respectively) as well as post-SRS complications such as hemorrhage, seizure, and headache (VRAS Scores 0-2, 3, and 4 resulted in complication rates of $8 \%, 24 \%$, and $29 \%$, respectively). ${ }^{11}$ We have performed an external validation of the VRAS in a multicenter cohort of over 2000 AVM patients treated with SRS. ${ }^{29}$ The study was performed under the auspices of the IGKRF, and the findings from this study demonstrate superiority of the VRAS over the SM or RBAS systems in terms of predicting SRS outcomes in AVM patients. ${ }^{29}$

\section{Study Limitations}

This study represents a large series of patients who had documentation of AVM obliteration after SRS. Our analysis remains limited by the retrospective nature of the data collected from each of the participating institutions. Some of the data (from the University of Pittsburgh and the University of Virginia) were previously used to construct ra- diosurgical AVM grading schemes (namely, the RBAS and VRAS, respectively). These overlapping cohorts represent a potential source for bias, but the length of follow-up in the current cohort is longer than those used to derive the original grading scales. Another related limitation stems from the fact that participating centers in this study are high-volume, tertiary care centers with long track records of performing SRS. It is possible that the results achieved herein may not be generalizable to other lower-volume centers.

The multicenter nature of this study and its large cohort precluded all clinical and treatment details from being logged. Thus, the exact nature of prior radiotherapy employed is not detailed. The exact dose, treatment scheme, or modality of prior radiotherapy is unknown and serves as a limitation. The obliteration response was confirmed by either angiography or MRA, which has been shown to be a reasonable substitute for digital subtraction angiography in determining obliteration. ${ }^{16}$ An additional study limitation stems from the varied SRS treatment strategies used in the different Gamma Knife centers. These differences can manifest in a higher or lower standard nidus prescription dose or smaller or larger nidus coverage. Despite the study's limitations, its multicenter design allows our findings to be generalizable to most AVM patients who are being considered for radiosurgery.

\section{Conclusions}

Arteriovenous malformation patients with an early versus late response to SRS are distinctly different. An early response ( $\leq 18$ months post-SRS) is more likely in patients without prior radiotherapy or with prior subtotal microsurgical resection. Early response was noted in patients whose nidus volume was smaller and in those whose AVM was located in the frontal lobe, basal ganglia, or cerebellum. Patients with deep venous drainage or whose AVM margin dose equaled or exceeded $24 \mathrm{~Gy}$ responded earlier. In this study cohort, we found that the VRAS outcome methodology could predict early obliteration for cerebral AVM patients treated with SRS.

\section{Acknowledgments}

We acknowledge the assistance of Ms. Lisa Baxendall, the clinical coordinator for the IGKRF.

\section{References}

1. Cohen-Inbar O, Lee CC, Xu Z, Schlesinger D, Sheehan JP: A quantitative analysis of adverse radiation effects following Gamma Knife radiosurgery for arteriovenous malformations. J Neurosurg 123:945-953, 2015

2. Colombo F, Pozza F, Chierego G, Casentini L, De Luca G, Francescon P: Linear accelerator radiosurgery of cerebral arteriovenous malformations: an update. Neurosurgery 34:14-21, 1994

3. Ding D, Yen CP, Xu Z, Starke RM, Sheehan JP: Radiosurgery for patients with unruptured intracranial arteriovenous malformations. J Neurosurg 118:958-966, 2013

4. Duma CM, Lunsford LD, Kondziolka D, Bissonette DJ, Somaza S, Flickinger JC: Radiosurgery for vascular 
malformations of the brain stem. Acta Neurochir Suppl 58:92-97, 1993

5. Fine JP, Gray RJ: A proportional hazards model for the subdistribution of a competing risk. J Am Stat Assoc 94:496-509, 1999

6. Flickinger JC, Pollock BE, Kondziolka D, Lunsford LD: A dose-response analysis of arteriovenous malformation obliteration after radiosurgery. Int J Radiat Oncol Biol Phys 36:873-879, 1996

7. Friedman WA, Bova FJ: Linear accelerator radiosurgery for arteriovenous malformations. J Neurosurg 77:832-841, 1992

8. Fukuoka S, Takanashi M, Seo Y, Suematsu K, Nakamura J: Radiosurgery for arteriovenous malformations with GammaKnife: a multivariate analysis of factors influencing the complete obliteration rate. J Clin Neurosci 5 Suppl:68-71, 1998

9. Gray RJ: A class of K-sample tests for comparing the cumulative incidence of a competing risk. Ann Stat 16:11411154,1988

10. Gross BA, Du R: Natural history of cerebral arteriovenous malformations: a meta-analysis. J Neurosurg 118:437-443, 2013

11. Huo X, Jiang Y, Lv X, Yang H, Zhao Y, Li Y: Gamma Knife surgical treatment for partially embolized cerebral arteriovenous malformations. J Neurosurg 7:1-10, 2015

12. Inoue HK, Nagaseki Y, Naitou I, Negishi M, Hirato M, Shibazaki T, et al: The role of intravascular embolization prior to radiosurgery of cerebral arteriovenous malformations from the standpoint of hemorrhage and early obliteration after Gamma Knife radiosurgery. Interv Neuroradiol 5 (Suppl 1):171-176, 1999

13. Kano H, Kondziolka D, Flickinger JC, Yang HC, Flannery TJ, Awan NR, et al: Stereotactic radiosurgery for arteriovenous malformations, Part 3: outcome predictors and risks after repeat radiosurgery. J Neurosurg 116:21-32, 2012

14. Kemeny AA, Dias PS, Forster DM: Results of stereotactic radiosurgery of arteriovenous malformations: an analysis of 52 cases. J Neurol Neurosurg Psychiatry 52:554-558, 1989

15. Kjellberg RN, Hanamura T, Davis KR, Lyons SL, Adams $\mathrm{RD}$ : Bragg-peak proton-beam therapy for arteriovenous malformations of the brain. N Engl J Med 309:269-274, 1983

16. Lee CC, Reardon MA, Ball BZ, Chen CJ, Yen CP, Xu Z, et al: The predictive value of magnetic resonance imaging in evaluating intracranial arteriovenous malformation obliteration after stereotactic radiosurgery. J Neurosurg 123:136-144, 2015

17. Lunsford LD, Kondziolka D, Flickinger JC, Bissonette DJ, Jungreis CA, Maitz AH, et al: Stereotactic radiosurgery for arteriovenous malformations of the brain. J Neurosurg 75:512-524, 1991

18. Maruyama K, Kawahara N, Shin M, Tago M, Kishimoto J, Kurita H, et al: The risk of hemorrhage after radiosurgery for cerebral arteriovenous malformations. N Engl J Med 352:146-153, 2005

19. Meder JF, Oppenheim C, Blustajn J, Nataf F, Merienne L, Lefkoupolos D, et al: Cerebral arteriovenous malformations: the value of radiologic parameters in predicting response to radiosurgery. AJNR Am J Neuroradiol 18:1473-1483, 1997

20. Monaco EA III, Niranjan A, Kano H, Flickinger JC, Kondziolka D, Lunsford LD: Management of adverse radiation effects after radiosurgery for arteriovenous malformations. Prog Neurol Surg 27:107-118, 2013

21. Nagaraja S, Lee KJ, Coley SC, Capener D, Walton L, Kemeny AA, et al: Stereotactic radiosurgery for brain arteriovenous malformations: quantitative MR assessment of nidal response at 1 year and angiographic factors predicting early obliteration. Neuroradiology 48:821-829, 2006
22. Ondra SL, Troupp H, George ED, Schwab K: The natural history of symptomatic arteriovenous malformations of the brain: a 24-year follow-up assessment. J Neurosurg 73:387391, 1990

23. Oppenheim C, Meder JF, Trystram D, Nataf F, Godon-Hardy S, Blustajn J, et al: Radiosurgery of cerebral arteriovenous malformations: is an early angiogram needed? AJNR Am J Neuroradiol 20:475-481, 1999

24. Petereit D, Mehta M, Turski P, Levin A, Strother C, Mistretta C, et al: Treatment of arteriovenous malformations with stereotactic radiosurgery employing both magnetic resonance angiography and standard angiography as a database. Int J Radiat Oncol Biol Phys 25:309-313, 1993

25. Pollock BE, Flickinger JC, Lunsford LD, Maitz A, Kondziolka D: Factors associated with successful arteriovenous malformation radiosurgery. Neurosurgery 42:1239-1247, 1998

26. Pollock BE, Gorman DA, Brown PD: Radiosurgery for arteriovenous malformations of the basal ganglia, thalamus, and brainstem. J Neurosurg 100:210-214, 2004

27. Schneider BF, Eberhard DA, Steiner LE: Histopathology of arteriovenous malformations after Gamma Knife radiosurgery. J Neurosurg 87:352-357, 1997

28. Spetzler RF, Martin NA: A proposed grading system for arteriovenous malformations. J Neurosurg 65:476-483, 1986

29. Starke RM, Kano H, Ding D, Lee JY, Mathieu D, Whitesell $\mathrm{J}$, et al: Stereotactic radiosurgery for arteriovenous malformations: a multicenter evaluation of grading scales and long-term outcomes. J Neurosurg [epub ahead of print March 4, 2016. DOI: 10.3171/2015.9.JNS151311]

30. Starke RM, Yen CP, Ding D, Sheehan JP: A practical grading scale for predicting outcome after radiosurgery for arteriovenous malformations: analysis of 1012 treated patients. J Neurosurg 119:981-987, 2013

31. Steinberg GK, Fabrikant JI, Marks MP, Levy RP, Frankel KA, Phillips MH, et al: Stereotactic heavy-chargedparticle Bragg-peak radiation for intracranial arteriovenous malformations. N Engl J Med 323:96-101, 1990

32. Szeifert GT, Levivier M, Lorenzoni J, Nyáry I, Major O, Kemeny AA: Morphological observations in brain arteriovenous malformations after Gamma Knife radiosurgery. Prog Neurol Surg 27:119-129, 2013

33. Szeifert GT, Timperley WR, Forster DM, Kemeny AA: Histopathological changes in cerebral arteriovenous malformations following Gamma Knife radiosurgery. Prog Neurol Surg 20:212-219, 2007

34. Taeshineetanakul P, Krings T, Geibprasert S, Menezes R, Agid R, Terbrugge KG, et al: Angioarchitecture determines obliteration rate after radiosurgery in brain arteriovenous malformations. Neurosurgery 71:1071-1079, 2012

35. Yamamoto M, Jimbo M, Ide M, Lindquist C, Steiner L: Postradiation volume changes in gamma unit-treated cerebral arteriovenous malformations. Surg Neurol 40:485-490, 1993

36. Yamamoto M, Jimbo M, Kobayashi M, Toyoda C, Ide M, Tanaka N, et al: Long-term results of radiosurgery for arteriovenous malformation: neurodiagnostic imaging and histological studies of angiographically confirmed nidus obliteration. Surg Neurol 37:219-230, 1992

37. Yamamoto Y, Coffey RJ, Nichols DA, Shaw EG: Interim report on the radiosurgical treatment of cerebral arteriovenous malformations. The influence of size, dose, time, and technical factors on obliteration rate. J Neurosurg 83:832-837, 1995

38. Yen CP, Schlesinger D, Sheehan JP: Natural history of cerebral arteriovenous malformations and the risk of hemorrhage after radiosurgery. Prog Neurol Surg 27:5-21, 2013 


\section{Disclosures}

Dr. Grills has stock ownership in and serves on the Board of Directors for the Greater Michigan Gamma Knife Company. Dr. Lunsford owns stock in Elekta AB.

\section{Author Contributions}

Conception and design: Sheehan, Cohen-Inbar. Acquisition of data: Cohen-Inbar, Starke, Paisan, Kano, Huang, Rodriquez-

Mercado, Almodovar, Grills, Mathieu, Silva, Abbassy, Missios, Lee, Barnett, Kondziolka. Analysis and interpretation of data:
Sheehan, Cohen-Inbar, Starke. Drafting the article: Cohen-Inbar, Paisan. Critically revising the article: Sheehan, Cohen-Inbar, Starke, Barnett, Kondziolka, Lunsford. Reviewed submitted version of manuscript: Sheehan, Cohen-Inbar, Starke, Kano, Huang, Rodriquez-Mercado, Almodovar, Grills, Mathieu, Abbassy, Missios, Lee, Barnett, Kondziolka, Lunsford. Statistical analysis: Sheehan, Starke. Administrative/technical/material support: Sheehan. Study supervision: Sheehan.

\section{Correspondence}

Jason Sheehan, Department of Neurological Surgery, University of Virginia, Box 800212, Charlottesville, VA 22908. email: jsheehan@virginia.edu. 